\title{
Retracted
}

\section{El discurso por competencias: Una propuesta de clarificación conceptual}

\author{
Ignasi Brunet Icart(iD, Liviu Catalin Mara (iD) \\ Universitat Rovira i Virgili (Spain) \\ ignasi.brunet@,urv.cat, liviucatalin.mara@urv.cat
}

Received March, 2016

Accepted August, 2016

Open investigation: 22 $2^{\text {nd }}$ October 2016

Retraction: $21^{\text {st }}$ November 2016

El 25 de octubre de 2016, se informa a los autores del artículo que siguiendo los protocolos editoriales de la revista Intangible Capital y de la editorial OmniaScience se había abierto una investigación por posible autoplagio y plagio, dando la posibilidad a dichos autores de exponer su argumentos. En dicho informe se adjuntaban las principales referencias no citadas:

Altaba Dolz, E. (2010). La nuevas gestión públicas y la gestión por competencias. Tesis doctoral. Universitat Rovira i Virgili. ISBN: 978-84-693-0688-8 DL: T-416-2010.

García-Abad Espejo, I., Ibáñez Pascual. I. (2006). Competencias para el empleo: Demandas de las empresas y medición de los desajustes. Revista Internacionl de Sociología (RIS), LXIV, 43, enero-abril, 139-168.

Brunet, I., Böcker Zavaro, R. (2014). Competitividad, competencias y finalidad de ciclo fordista. Revista Internacional de Sociología de la Educación, 3(1) enero-abril, 1-25. 
E1 25 de octubre 2016 recibimos respuesta de uno de los autores, firmando en nombre de ambos, indicando que piden disculpas:

"El artículo publicado en su revista es una propuesta de clarificación conceptual por lo que se han seleccionado y utilizado las referencias bibliográficas más significativas, explícitamente expuestas en el artículo que la revista Intangible Capital publicó. Por ello nos parece absurdo culpabilizarnos de copiar y pegar textos de trabajos sobre los que no tenemos autoría, cuando el objetivo del artículo es una propuesta de clarificación conceptual dada la variedad de perspectivas que hay en la literatura en torno a las competencias. Esta variedad queda reflejada en el artículo, sino se nos podría acusar de ignorar parte de la literatura.

Finalmente, lamentamos esta situación y pedimos disculpas, por anticipado, si hemos cometido alguna falta grave. También suponemos que la denuncia es anónima y que detrás hay una voluntad manifiesta de difamación.”

El 21 de Noviembre 2016, informamos a los autores que una vez escuchados los argumentos, y siguiendo las directrices editoriales y de ética editorial procedemos a retractar el artículo. 